\title{
APRESENTAÇÃO
}

\section{A história, a formação e o ensino das Ciências Sociais como tema de pesquisa}

Amurabi Oliveira

O que convencionamos denominar de "ciências sociais" possui diferentes sentidos dentro dos diversos contextos nacionais e temporais; no caso brasileiro, esse termo passa a se consolidar ainda na década de 1930 quando emergem as primeiras graduações que passam a outorgar o título de bacharel em ciências sociais. No entanto, é válido rememorar que as Faculdades de Direito outorgavam o título de bacharel em "ciências jurídicas e sociais" desde o século XIX, o que aponta para certa continuidade entre tais campos de formação.

É certo que os cursos de ciências sociais são criados com a ideia de formação de elites intelectuais, que passariam a se especializar na análise dos "problemas sociais" que estavam cada vez mais em evidência nas primeiras décadas do século XX, porém tal especialização dar-se-ia a partir de uma perspectiva profundamente multidisciplinar, uma vez que tais cursos abarcavam discussóes que incluíam a Antropologia, Ciência Política, Demografia, História, Geografia, Psicologia Social, Sociologia etc. Essa compreensão mais alargada de ciências sociais fica evidente quando analisamos alguns dados, como o fato do curso de ciências sociais da Universidade do Distrito Federal ter três habilitaçóes: História, Geografia e Sociologia, ou

$(\infty)$ EY
Direito autoral e licença de uso: Este artigo está licenciado sob uma Licença Creative Commons. Com essa licença você pode compartilhar, adaptar, para qualquer fim, desde que atribua a autoria da obra, forneça um link para a licença, e indicar se foram feitas alterações. 
ainda ao considerarmos a criação da divisão de estudos pós-graduados na Escola Livre de Sociologia e Política de São Paulo, que abarcava cursos tão distintos quanto Sociologia, Estatística, Psicologia Social etc. .

Levanto como hipótese a ideia de que uma compreensão de ciências sociais mais restrita à antropologia, à ciência política e à sociologia passa a se consolidar a partir da década de 1950, quando a disseminaçáo das Faculdades de Filosofia, Ciências e Letras - que tomava a Universidade do Brasil como modelo - impulsiona a ampliação do número de cursos de graduação em história e geografia, esvaziando essa dimensão formativa dos cursos de ciências sociais, ainda que continuem a existir cátedras nestas áreas em tais cursos, compondo uma dimensão formativa importante, porém não mais central. Esse cenário consolida-se na década de 1970, com o advento dos programas de pós-graduação, que passam a garantir a existência de uma formação acadêmica disciplinar nestas áreas².

No contexto mais recente, ainda considerando o caso brasileiro, temos o desenvolvimento de uma aproximação mais enfática entre as ciências sociais e a temática do ensino. Ainda que se possa argumentar que o debate sobre o ensino das ciências sociais sempre se fez presente de alguma forma no Brasil - vide os primeiros congressos da Associação Brasileira de Antropologia (ABA) e da Sociedade Brasileira de Sociologia (SBS) - torna-se patente que o processo de expansão recente dos cursos de graduaçáo na área, especialmente de licenciaturas, e da reintrodução da sociologia no currículo escolar em nível nacional a partir de 2008 foram fatores que redimensionaram o debate.

Ainda que partamos essencialmente do contexto brasileiro para pensar tais questóes, como veremos mais adiante, neste número da revista Política \& Sociedade buscamos internacionalizar o debate, agregando discussóes que partem de outros contextos nacionais, como o argentino, francês, norte-americano e uruguaio.

I Os primeiros cursos de ciências sociais criados no Brasil ainda na década de 1930 foram os da Escola Livre de Sociologia e Política de São Paulo (1933), Universidade de São Paulo (1934), Universidade do Distrito Federal (UDF) e a Faculdade de Filosofia, Ciências e Letras do Paraná (1938).

2 Apesar do fato de terem sido defendidas no Brasil teses na área de ciências sociais ainda na década de 1940, apenas com a Reforma Universitária de 1968 que passamos a ter cursos regulares de mestrado e doutorado no Brasil, nos quais os estudantes precisam realizar disciplinas além de produzir a tese, seguindo um conjunto de práticas que rotinizaram determinada forma de produção da pesquisa em ciências sociais no Brasil. 
Considerando esse contexto brevemente posto aqui, neste dossiê será assumida a perspectiva que atualmente se encontra como predominante no campo acadêmico brasileiro, que compreende as ciências sociais a partir da antropologia, ciência política e sociologia. Neste sentido, os artigos aqui reunidos têm como eixos norteadores as questóes relacionadas à história, à formação e ao ensino de tais ciências, em um sentido alargado do termo.

Abrindo o debate proposto pelo dossiê, temos a entrevista concedida por Carlos Benedito Martins, professor titular da Unb e atual presidente SBS, no qual ele náo apenas apresenta sua trajetória acadêmica, como também realiza uma análise perspicaz acerca da sociologia da educação no Brasil e da própria sociologia brasileira como um todo, realizando um exercício de "sociologia da sociologia".

O primeiro artigo que compóe esse dossiê intitula-se "Revisitando o Museu Nacional e a história da Antropologia no Brasil pelas mãos de Heloísa Alberto Torres", de Adélia Miglievich-Ribeiro, o qual revisita a história da primeira instituição de pesquisa brasileira, que sofreu um grave incêndio em 2018, tornando-se notícia na mídia internacional. Neste trabalho analisa-se a trajetória de Heloisa Alberto Torres, que fora diretora do Museu Nacional, apontando para seu protagonismo na formulação das ciências sociais brasileiras, o que é conduzido a partir de um olhar cuidadoso em torno de suas experiências sociais.

Seguindo a esteira de uma contribuição à história das ciências sociais, porém em outro contexto nacional, Juan Pedro Blois, em "Disputas en torno al ensayismo en la sociología argentina (1950s-1970s)", analisa como os sociólogos argentinos se posicionaram ante ao ensaísmo no período compreendido entre as décadas de 1950 e 1970, que se tensionou desde uma marcada oposição, no contexto da institucionalização científica da disciplina, até um processo de recuperação desse ensaísmo para a produção e promoçáo de uma "sociologia nacional". Desse modo, o autor dar relevo às complexas relaçóes que a sociologia argentina estabeleceu com o ensaísmo no período analisado.

Por outro lado, Rodrigo Bordignon, em "Trajetos escolares e destinos profissionais: o caso das ciências sociais no Brasil", por meio da análise de correspondência múltiplas (ACM), realiza uma investigaçáo sobre a 
relação entre as diferentes modalidades de trajeto escolar e as hierarquias dos cursos e das instituiçóes de destino, tomando como escopo empírico o conjunto dos professores vinculados aos programas de pós-graduação nas áreas de antropologia e arqueologia, ciência política e relaçóes internacionais e sociologia. Nesse estudo ele aponta que as conexóes entre instituições de origem e de destino são dependentes das relaçóes entre centro e periferia em nível nacional e internacional, impactando nas chances de acesso às carreiras e de afirmação no campo das ciências sociais.

Voltando-se especificamente para a formação doutoral em sociologia no período recente, Marina Félix de Melo, Selefe Gomes da Silva Neta e Rúbia Carmita do Nascimento, em "As metodologias dos recém-doutores dos programas de pós-graduação em sociologia: das disciplinas às teses”, utilizam de análise documental (a partir de ementas de disciplinas) e a análise de conteúdo (a partir de entrevistas realizadas) para pensar como os recém-doutores têm se utilizado recursivamente de métodos e técnicas de pesquisa para realizar suas pesquisas. As autoras apontam que os problemas de pesquisa das teses de sociologia não determinam os métodos a serem utilizados nos trabalhos, sendo tais métodos determinados pelas condiçôes de competências técnicas e de formação dos pesquisadores e por dimensôes relacionadas a fatores relacionais entre os atores e a vida acadêmica.

O trabalho intitulado "Licenciados e licenciadas em Ciências Sociais na UFSC: Experiências, sentidos e trajetórias", de Eduardo Bolnaldi e, utiliza de entrevista em profundidade, realizadas com egressos do curso de licenciatura em ciências sociais da Universidade Federal de Santa Catarina, graduados a partir dos anos 2000, para pensar questóes que tangenciam desde a escolha pelo curso, passando pelos "ganhos não materiais" apontados pelos entrevistados. O autor destaca o efeito socializador do curso, e de como isso impacta na percepção que os entrevistados produzem de suas próprias trajetórias no curso.

Tratando também da formação em uma licenciatura em ciências sociais, Ceres Karam Brum em "Os 10 anos da Sociologia no ensino médio no Brasil: considerações sobre a formação de professores de Ciências Sociais na UFSM" parte de uma experiência particular, marcada pela configuração do departamento de ciências sociais da Universidade Federal de 
Santa Maria (UFSM) no interior do Rio Grande do Sul, e por seu trajeto nas disciplinas de "Ciências Sociais para o Ensino Médio" e "Antropologia da Educação". E ante ao contexto que se desenha, o qual aponta para evidentes ameaças à consolidação da presença da sociologia no currículo escolar, a autora propóe um diálogo com os conceitos antropológicos de aprendizagem e cultura, como uma possibilidade à formação de professores nesse campo.

O artigo "Educação e expertise. A sociologia como 'profissão' nos Estados Unidos", de autoria de William Buxton e Stephen Turner, também se volta para a formação de quadros em sociologia; porém, voltando-se para os diferentes sentidos que a formação sociológica assume nos Estados Unidos ao longo do século XX. Os autores analisam detalhadamente tanto a concepção de Talcott Parsons da sociologia como uma "profissão" como o contexto de Harvard onde ela foi idealizada. Eles apontam que o modelo de Parsons teve alguns êxitos organizativos interessantes, tendo sido um elemento essencial na proposta mais ampla da sociologia que emergia do revelador relatório de Parsons sobre a profissão sociológica de 1959 , às vésperas da grande expansão da sociologia. Contudo, o sucesso teria sido passageiro.

Amurabi Oliveira, em "O Ensino de Sociologia no Uruguai: uma análise a partir das narrativas dos professores", parte de um conjunto de entrevistas realizado com professores de sociologia que atuam no ensino médio uruguaio, para traçar alguns elementos comparativos com a realidade brasileira. Nesta pesquisa, observa-se que os professores uruguaios de sociologia consolidam uma identidade docente ainda em sua formação inicial, considerando inclusive a particularidade do modelo formativo docente uruguaio, realizado de forma apartada da formação de bacharéis. Todavia, evidencia-se um recorte geracional entre aqueles que realizaram a formação antes e depois de 2008, quando o curso passou a assumir um contorno mais disciplinar, distanciando-se da formaçáo no campo do direito.

Por fim, o trabalho "Ensinar Pierre Bourdieu no 9-3: o que falar quer dizer", de Fabien Truong, parte de uma experiência do autor, lecionando o tema da "reprodução" em Pierre Bourdieu na disciplina de ciências econômicas e sociais em um liceu francês na periferia parisiense. Trazendo 
elementos a partir de suas observaçóes, bem como meio das falas de seus alunos, apontando para a forma como os estudantes reagem à teoria da reprodução do Bourdieu, Truong elabora reflexôes relevantes sobre o ensino das teorias sociológicas no contexto escolar, especialmente em cenários de desigualdade social.

Observa-se, assim, que esse conjunto de trabalhos trazem reflexóes originais sobre a história, formação e ensino das ciências sociais, demonstrando a relevância dessa temática como uma agenda de pesquisa autônoma. Ressalta-se que ganha especial relevância o debate aqui promovido no contexto dos recentes ataques às ciências humanas, e à sociologia em particular. Espero que os artigos instiguem novas questóes de pesquisa para os leitores, possibilitando uma renovação contínua dos problemas de pesquisa nessa seara.

Boa leitura 